ORIGINAL ARTICLE

\title{
Neuromuscular and biomechanical characteristic changes in high school athletes: a plyometric versus basic resistance program
}

\section{S M Lephart, J P Abt, C M Ferris, T C Sell, T Nagai, J B Myers, J J Irrgang}

Br J Sports Med 2005;39:932-938. doi: 10.1136/bjsm.2005.019083

See end of article for authors' affiliations

Correspondence to: Dr Scott M Lephart Neuromuscular Research Laboratory, UPMC Center for Sports Medicine, 3200 South Water Street, Pittsburgh, PA 15203, USA; lephart@pitt.edu

Accepted 3 May 2005

\begin{abstract}
Background: In order to improve neuromuscular and biomechanical characteristic deficits in female athletes, numerous injury prevention programs have been developed and have successfully reduced the number of knee ligament injuries. However, few have investigated the neuromuscular and biomechanical changes following these training programs. It is also largely unknown what type of program is better for improving the landing mechanics of female athletes.

Objectives: To investigate the effects of an 8 week plyometric and basic resistance training program on neuromuscular and biomechanical characteristics in female athletes.

Methods: Twenty seven high school female athletes participated either in a plyometric or a basic resistance training program. Knee and hip strength, landing mechanics, and muscle activity were recorded before and after the intervention programs. In the jump-landing task, subjects jumped as high as they could and landed on both feet. Electromyography (EMG) peak activation time and integrated EMG of thigh and hip muscles were recorded prior to (preactive) and subsequent to (reactive) foot contact.

Results: Both groups improved knee extensor isokinetic strength and increased initial and peak knee and hip flexion, and time to peak knee flexion during the task. The peak preactive EMG of the gluteus medius and integrated EMG for the gluteus medius during the preactive and reactive time periods were significantly greater for both groups.

Conclusions: Basic training alone induced favourable neuromuscular and biomechanical changes in high school female athletes. The plyometric program may further be utilised to improve muscular activation patterns.
\end{abstract}

A nterior cruciate ligament (ACL) injuries are more prevalent in female athletes compared with male athletes, particularly at the high school level. ${ }^{12}$ Neuromuscular and biomechanical characteristics presumed to be contributing risk factors to female ACL injuries have received considerable attention in recent years because of their potential for modification through prevention programs. ${ }^{3-5}$ Previous research has reported that female athletes landed with less knee flexion, less time to peak knee flexion, greater knee valgus, greater vertical ground reaction forces (vGRF), and less hamstring activation than male athletes. Females have also demonstrated decreased hamstrings and quadriceps strength and decreased proprioception. ${ }^{67}$

Numerous injury prevention programs have been developed to modify such neuromuscular and biomechanical characteristics in an attempt to reduce the number of ACL injuries in female athletes. ${ }^{8-13}$ Typically, these programs incorporate a combination of balance, plyometric, agility, resistance, and flexibility components and have successfully reduced the number of ACL injuries in females athletes. ${ }^{8-12}$ Although it was not specific to an ACL injury prevention program, Lehnhard et al ${ }^{13}$ reported a reduction in sprains after implementing a basic resistance training program alone, suggesting that injury prevention can be achieved by regular strength training. While the previous prospective studies demonstrated the importance of injury prevention programs for female athletes, they did not address the specific neuromuscular and biomechanical adaptations that occurred following participation in each training program. It is uncertain which component of these training programs is the most important to maximise the effects and efficacy of an ACL injury prevention program.
To our knowledge, few studies ${ }^{14}{ }^{15}$ have reported the neuromuscular and biomechanical characteristic changes following an ACL injury prevention program; and no study has made neuromuscular and biomechanical comparisons between plyometric and basic resistance training programs. Therefore, the purpose of the current study was to identify the neuromuscular and biomechanical adaptations that result from an 8 week plyometric and basic resistance training programs in high school female athletes with similar age, sport, and training backgrounds. We hypothesised that both training programs would result in favourable neuromuscular and biomechanical adaptations including an increase in knee flexor and extensor strength, a decrease in vGRF, an increase in knee and hip flexion, a decrease in knee valgus and hip adduction, and a decrease in knee valgus and hip adduction moments during a jump-landing task. We also hypothesised that the plyometric program would further induce increased muscle preactivity prior to force plate contact and heightened reactive muscular activity in the hamstrings musculature, compared with the basic resistance program.

\section{METHODS}

All subjects reported to the laboratory on two separate occasions before and after the 8 week intervention programs. Each test consisted of an isokinetic knee flexion and extension torque assessment, isometric hip abduction torque assessment, and drop-landing assessment.

Abbreviations: $\mathrm{ACL}$, anterior cruciate ligament; $\mathrm{EMG}$, electromyography; MIVC, maximal voluntary isometric contraction; vGRF, vertical ground reaction forces 


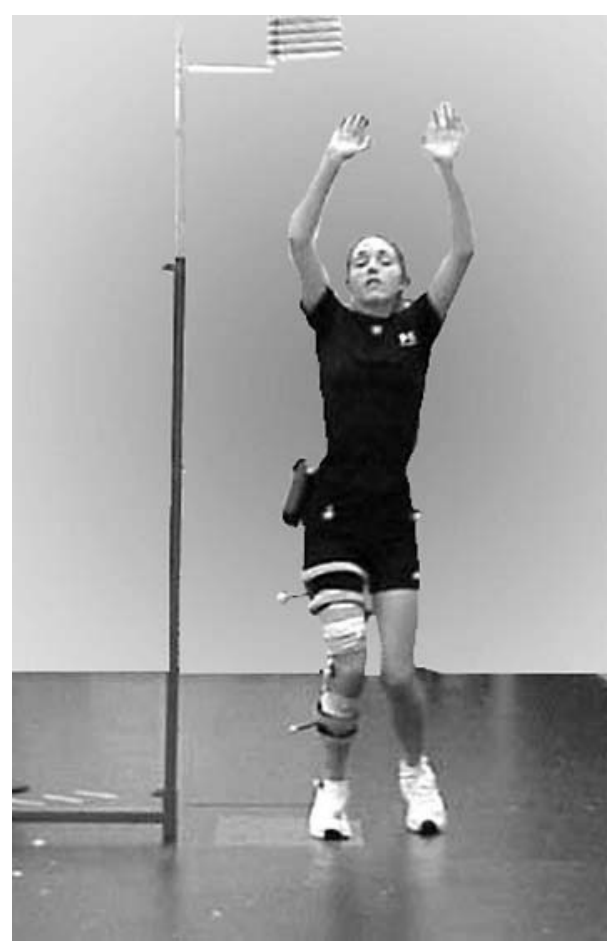

Figure 1 Jump-landing task. (Photograph reproduced with permission.)

\section{Subjects}

Twenty seven healthy, female athletes were recruited from local area high schools. Subjects provided written informed consent prior to participation in accordance with the University Institutional Review Board. Subjects were randomly assigned to either a plyometric or basic resistance group. Subject demographics (number of subjects, age, height, and mass) for each group are as follows: plyometric group $(\mathrm{n}=14,14.5 \pm 1.3$ years, $1.65 \pm 0.06 \mathrm{~m}$ tall, and $55.1 \pm 8.0 \mathrm{~kg})$ and basic resistance group $(\mathrm{n}=13,14.2 \pm 1.3$ years, $1.66 \pm 0.08 \mathrm{~m}$ tall, and $58.3 \pm 10.8 \mathrm{~kg}$ ). All subjects participated in nationally or locally organised basketball or soccer club teams. Subjects reporting a history of serious knee injury or other lower extremity injury within the previous 6 months were excluded.

\section{Instrumentation}

Isokinetic knee and isometric hip strength data of the dominant limb were collected with the Biodex System 3 Multi-Joint Testing and Rehabilitation System (Biodex Medical, Shirley, NY). Torque values were automatically adjusted for gravity by Biodex Advantage Software version 3.0 (Biodex Medical). Limb dominance was defined by the leg used to kick a ball. ${ }^{16}$

EMG activity of the dominant limb was measured with the Noraxon Telemyo System (Noraxon USA, Scottsdale, AZ). Pre-gelled bipolar (Ag/AgCl) surface electrode discs (Medicotest, Rolling Meadows, IL) were positioned on the muscle belly of the vastus medialis, vastus lateralis, medial hamstring, lateral hamstring, and gluteus medius. Visual inspection of the raw EMG signal was performed on an oscilloscope during an isolated manual muscle test to confirm correct positioning of the electrodes. EMG signals were passed from a portable battery operated FM transmitter worn by the subject to a receiver (gain 500 , band pass filtered $15-$ $500 \mathrm{~Hz}$, common mode rejection ratio of $130 \mathrm{~dB}$ ), converted from analog to digital data, and stored on a personal computer for processing. EMG data were sampled at a rate

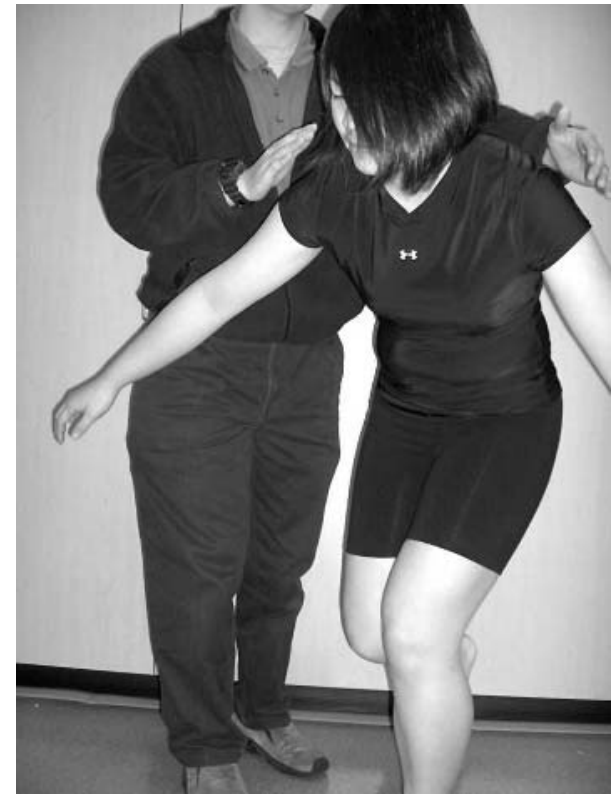

Figure 2 Single leg balance with perturbations. (Photograph reproduced with permission.)

of $1200 \mathrm{~Hz}$ during both functional tasks. A maximal voluntary isometric contraction (MIVC) was collected for each muscle to be used for normalisation of the EMG during the data collection trials.

Raw coordinate and force data were collected using the Peak Motus 3D Motion Analysis System (software version 6.03, Peak Performance Technologies, Englewood, CO) interfaced with six high speed $(120 \mathrm{~Hz})$ optical cameras (Pulnix Industrial Product Division, Sunnyvale, CA) and an in-ground force plate (Bertec, Worthington, $\mathrm{OH}$ ). The capture volume of $4.5 \times 1.5 \times 2.1 \mathrm{~m}^{3}$ was calibrated using a wand method (wand length $0.914 \mathrm{~m}$ ) with a mean residual error range of $1.2-1.9 \mathrm{~mm}$. Coordinate and force data were collected at 120 and $1200 \mathrm{~Hz}$, respectively. Linear and circumferential anthropometric measurements of the dominant lower extremity were recorded for each subject. Retroreflective markers (diameter $0.025 \mathrm{~m}$ ) were placed at designated anatomical landmarks as described by Vaughan $e t$ al. ${ }^{17}$ Two additional markers were attached to wands (at a distance of $0.09 \mathrm{~m}$ from the skin) and placed at the lateral side of the mid-thigh and mid-calf.

\section{Protocols: peak torque and landing assessment}

For knee strength testing, subjects were seated in the Biodex chair and secured using thigh, pelvic, and torso straps to minimise accessory and compensatory movements during the knee strength testing. The lateral femoral epicondyle of the dominant limb was aligned with the dynamometer's axis of rotation. Subjects performed isokinetic extension and flexion concentric contractions at $60 \%$ and $180 \%$ after practice sessions. The peak torque was normalised with their body mass for the quadriceps and hamstrings for each speed. During MVIC for quadriceps and hamstrings testing, the testing leg was positioned at $45^{\circ}$ of knee flexion, and the peak torque and EMG were recorded for $5 \mathrm{~s}$.

Isometric hip abduction strength was assessed in a sidelying position with the centre of the greater trochanter aligned with the dynamometer's axis of rotation. Subjects were secured using torso and pelvic straps. Subjects performed three $5 \mathrm{~s}$ maximal isometric contraction at $0^{\circ}$ of hip abduction. 
Table 1 Pre and post training: strength data

\begin{tabular}{|c|c|c|c|}
\hline Strength & & $\begin{array}{l}\text { Pretest } \\
\text { (\%BW) }\end{array}$ & $\begin{array}{l}\text { Post-test } \\
\text { (\%BW) }\end{array}$ \\
\hline $\begin{array}{l}\text { Quadriceps peak } \\
\text { torque, } 60^{\circ} / \mathrm{s}^{*} \\
\text { Hamstrings peak } \\
\text { torque, } 60^{\circ} \% \mathrm{~s} \\
\text { Quadriceps peak } \\
\text { torque, } 180^{\circ} / \mathrm{s}^{*} \\
\text { Hamstrings peak } \\
\text { torque, } 180^{\circ} / \mathrm{s} \\
\text { Hip abduction } \\
\text { isometric peak } \\
\text { torque }\end{array}$ & $\begin{array}{l}\text { Plyometric } \\
\text { Basic } \\
\text { Plyometric } \\
\text { Basic } \\
\text { Plyometric } \\
\text { Basic } \\
\text { Plyometric } \\
\text { Basic } \\
\text { Plyometric } \\
\text { Basic }\end{array}$ & $\begin{array}{r}211.8 \pm 45.2 \\
187.6 \pm 35.4 \\
106.3 \pm 32.6 \\
103.6 \pm 16.6 \\
154.1 \pm 26.5 \\
128.5 \pm 22.9 \\
88.4 \pm 23.7 \\
75.9 \pm 11.1 \\
169.4 \pm 34.1 \\
140.9 \pm 36.0\end{array}$ & $\begin{array}{r}227.6 \pm 23.9 \\
207.7 \pm 33.8 \\
112.7 \pm 14.4 \\
110.6 \pm 23.0 \\
162.3 \pm 17.9 \\
147.2 \pm 18.1 \\
83.6 \pm 16.3 \\
88.2 \pm 20.3 \\
165.5 \pm 35.6 \\
158.8 \pm 51.1\end{array}$ \\
\hline
\end{tabular}

BW, body weight.

*Significant main effect pretest-posttest differences at $p<0.05$.

The jump-landing task (fig 1) consisted of a double legged vertical jump. Subjects were initially placed in a standing position with the dominant limb on the force plate and the non-dominant limb on the floor. Subjects were instructed to perform a maximal effort vertical jump and land on the force plate. Subjects were provided with a verbal description and visual demonstration of the task, and practised to familiarise themselves with the tasks prior to the testing. Limited landing instructions were provided to promote natural performance of the task. Ten trials of each task were collected.

\section{Descriptions of the plyometric and basic programs (appendix A)}

An 8 week training protocol was designed specifically for female athletes to address previously identified deficient neuromuscular and biomechanical mechanisms that contribute to inadequate dynamic knee stability. ${ }^{3-5}$ Both the plyometric and basic training programs consisted of two, 4 week phases. Phase I was identical for both groups. It consisted of six lower extremity flexibility exercises (three repetitions each for $30 \mathrm{~s}), 11$ resistance exercises (20-30 repetitions each), and three balance (fig 2) exercises (three repetitions each for $15 \mathrm{~s}$ ). The plyometric group performed a different phase II than the basic group. Phase II for the plyometric group integrated 11 plyometric exercises (10 repetitions each) and seven agility training exercises (five repetitions each) into the existing training program. The basic training group's phase II progressed the phase I exercises by increasing the amount of time and number of repetitions for each exercise. Each exercise component was performed 3 days per week with the repetitions progressed between phases. Each training session typically took $30 \mathrm{~min}$. Exercise logs, a verbal description, and video demonstration $\mathrm{CD}$ were provided for all subjects. Bi-monthly meetings were held with all subjects to ensure compliance and proper performance of the exercises.

\section{Data reduction}

Raw three-dimensional coordinate and analog data were exported to MS3D version 4.5 (MotionSoft, Chapel Hill, NC) for further processing. Raw three-dimensional coordinate data were filtered using a low pass Butterworth 4th order, zero lag digital filter with an estimated cut-off frequency. ${ }^{18}$ Vertical ground reaction forces were calculated following time synchronisation of coordinate and analog data. Joint centres of the hip, knee, and ankle were estimated using three-dimensional coordinates of the markers. ${ }^{19}$ Kinematic and kinetic variables were analysed throughout the movement cycle at initial contact and peak vertical ground reaction force.

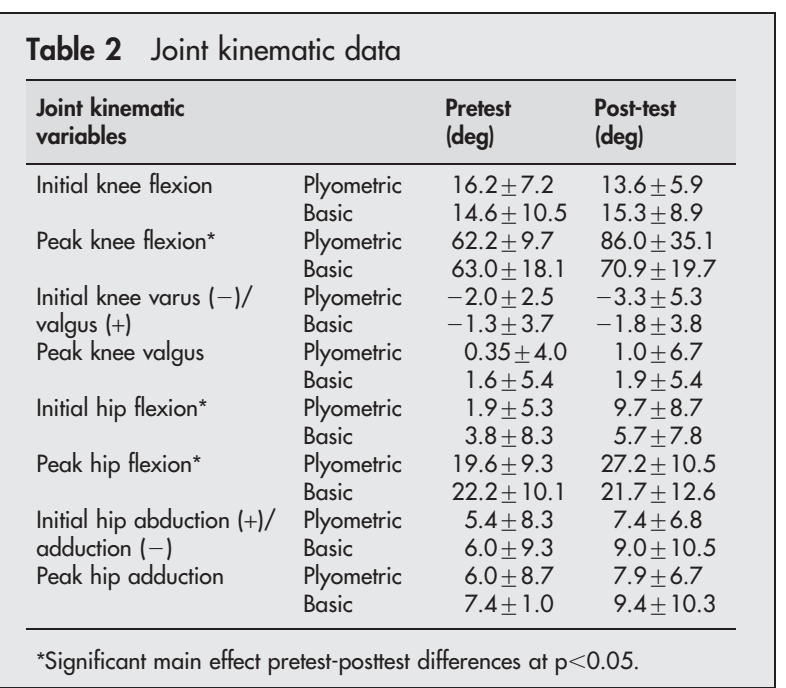

EMG data were recorded $150 \mathrm{~ms}$ prior to initial contact with the force plate and $150 \mathrm{~ms}$ following initial contact with the force plate for the jump-landing task. The onset time was determined as the time when EMG voltage passed above the mean plus 3 standard deviations of the resting trials. The raw MVIC data were processed using a linear envelope (fullwave rectified and low pass filtered 4th order, zero phase lag Butterworth with a $20 \mathrm{~Hz}$ cutoff). The peak amplitude of a $30 \mathrm{~ms}$ moving average was calculated and used to normalise all trial data. The time to peak EMG amplitude was calculated and reported as the time before (preactivity) and after the initial contact (reactivity). The raw trial data were processed using a linear envelope (fullwave rectified and low pass filtered 4th order, zero phase lag Butterworth with a $20 \mathrm{~Hz}$ cutoff). Integrated EMG data were calculated for each time interval and reported as \%MVIC*s.

\section{Statistical analysis}

Data were analysed with SPSS 11.0 (SPSS, Chicago, IL). Separate two way (group $\times$ session) repeated measures ANOVA were performed to assess differences in strength, kinematic, kinetic, ground reaction force, and EMG data. Statistical significance of $\mathrm{p}<0.05$ was set a priori.

\section{RESULTS}

Strength data are presented in table 1. Both groups demonstrated a significant improvement in peak quadriceps strength at $60 \%(p=0.007)$ and $180 \% \quad(p=0.006)$. No significant differences were noted in hamstring or hip abduction strength $(\mathrm{p}>0.05)$ between tests. No significant group (plyometric $v$ basic) differences were found for any strength variables.

Kinematic, kinetic, and ground reaction force data during a jump-landing task are presented in tables 2-4. Kinematically, both groups significantly increased hip flexion at initial contact $(p=0.016)$, peak hip flexion $(p=0.017)$, peak knee flexion $(p=0.009)$, and time to peak knee flexion $(p=0.006)$ between tests (fig 3). Kinetically, both groups significantly

Table 3 Ground reaction force data

\begin{tabular}{llll}
\hline $\begin{array}{l}\text { Ground } \\
\text { reaction force }\end{array}$ & $\begin{array}{l}\text { Pretest } \\
\text { (\%BW) }\end{array}$ & $\begin{array}{l}\text { Post-test } \\
\text { (\%BW) }\end{array}$ \\
\hline Peak vertical & $\begin{array}{l}\text { Plyometric } \\
\text { Basic }\end{array}$ & $\begin{array}{l}232.7 \pm 71.4 \\
206.3 \pm 71.0\end{array}$ & $223.0 \pm 57.9$ \\
& & & \\
\hline BW, body weight. & & \\
\hline
\end{tabular}


Table 4 Peak joint moment data

\begin{tabular}{|c|c|c|c|}
\hline $\begin{array}{l}\text { Joint moment } \\
\text { variables }\end{array}$ & & $\begin{array}{l}\text { Pretest } \\
\text { (Nm/BW*H) }\end{array}$ & $\begin{array}{l}\text { Post-test } \\
\left(\mathrm{Nm} / \mathrm{BW}^{*} \mathrm{H}\right)\end{array}$ \\
\hline $\begin{array}{l}\text { Peak knee } \\
\text { flexion moment* } \\
\text { Peak knee } \\
\text { valgus moment } \\
\text { Peak hip } \\
\text { flexion moment* } \\
\text { Peak hip adduction } \\
\text { moment }\end{array}$ & $\begin{array}{l}\text { Plyometric } \\
\text { Basic } \\
\text { Plyometric } \\
\text { Basic } \\
\text { Plyometric } \\
\text { Basic } \\
\text { Plyometric } \\
\text { Basic }\end{array}$ & $\begin{array}{c}0.076 \pm 0.038 \\
0.079 \pm 0.047 \\
0.039 \pm 0.017 \\
0.035 \pm 0.034 \\
0.17 \pm 0.058 \\
0.175 \pm 0.09 \\
0.063 \pm 0.042 \\
0.07 \pm 0.039\end{array}$ & $\begin{array}{l}0.059 \pm 0.01 \\
0.051 \pm 0.033 \\
0.025 \pm 0.013 \\
0.033 \pm 0.02 \\
0.153 \pm 0.033 \\
0.141 \pm 0.07 \\
0.064 \pm 0.026 \\
0.051 \pm 0.031\end{array}$ \\
\hline
\end{tabular}

BW, body weight; $\mathrm{H}$, height.

*Significant main effect pretest-posttest differences at $p<0.05$.

decreased the peak knee flexion moment $(p=0.013)$ and hip flexion moment $(p=0.008)$. No significant differences in vGRF were revealed between tests. No significant group differences existed for any kinematic, kinetic, or vGRF variables during the jump-landing task.

EMG jump-landing data are presented in tables 5 and 6 . The peak preactive EMG of the gluteus medius $(p=0.008)$ was significantly heightened for both groups between tests. The area under integrated EMG for the gluteus medius during the preactive $(p=0.016)$ and reactive $(p=0.008)$ periods was significantly greater for both groups. There was an interaction effect on the peak reactivity EMG time of the medial hamstring $(\mathrm{p}=0.028)$.

\section{DISCUSSION}

Quadriceps strength significantly improved for all subjects post-training, which is beneficial due to the noted quadriceps strength differences between males and females. ${ }^{3}{ }^{1420}$ The post-training peak quadriceps torques in the current study were similar to the previously reported values of Division I college female athletes. ${ }^{320}$ Although the hamstrings torque
Table 5 Peak preactivity and reactivity EMG time data

\begin{tabular}{lllr}
\hline EMG variables & & $\begin{array}{l}\text { Pretest } \\
\text { (ms) }\end{array}$ & \multicolumn{1}{l}{$\begin{array}{l}\text { Post-test } \\
\text { (ms) }\end{array}$} \\
\hline Vastus lateralis & Plyometric & $38.3 \pm 20.1$ & $7.5 \pm 17.2$ \\
preactivity & Basic & $50.0 \pm 25.1$ & $36.8 \pm 57.8$ \\
Vastus lateralis & Plyometric & $61.8 \pm 28.8$ & $70.3 \pm 25.8$ \\
reactivity & Basic & $64.8 \pm 23.4$ & $76.6 \pm 19.0$ \\
Medial hamstring & Plyometric & $40.9 \pm 25.5$ & $44.7 \pm 29.3$ \\
preactivity & Basic & $52.4 \pm 31.8$ & $61.4 \pm 37.9$ \\
Medial hamstring & Plyometric & $82.2 \pm 29.0$ & $57.5 \pm 33.4$ \\
reactivity† & Basic & $58.7 \pm 24.9$ & $71.2 \pm 42.3$ \\
Lateral hamstring & Plyometric & $30.0 \pm 24.3$ & $43.1 \pm 38.1$ \\
preactivity & Basic & $49.5 \pm 43.0$ & $45.6 \pm 39.5$ \\
Lateral hamstring & Plyometric & $74.0 \pm 23.7$ & $74.2 \pm 29.8$ \\
reactivity & Basic & $56.9 \pm 23.3$ & $86.4 \pm 31.5$ \\
Gluteus medius & Plyometric & $32.7 \pm 29.3$ & $34.9 \pm 40.7$ \\
preactivity* & Basic & $23.7 \pm 31.2$ & $66.9 \pm 43.7$ \\
Gluteus medius & Plyometric & $57.3 \pm 31.9$ & $49.6 \pm 33.4$ \\
reactivity & Basic & $46.5 \pm 23.3$ & $85.5 \pm 23.8$ \\
\hline
\end{tabular}

*Significant main effect pretest-posttest differences at $p<0.05$

tsignificant group interaction pretest-posttest differences at $p<0.05$.

improved approximately 6-7\%, the change was not significant. This finding is different from that reported by Hewett and colleagues ${ }^{14}$ who reported increased hamstrings torque after plyometric training. The differences observed between these two studies may be due to the differences in training protocols, intensity, and/or training duration.

Vertical ground reaction forces did not change significantly post-training in the current study, which was contrary to the hypothesis. Two studies have investigated the effect of plyometric training on $\mathrm{VGRF}$, and both reported a reduction in vGRF after training. ${ }^{14}$ Ground reaction forces are also influenced by the application of proper techniques, and have been reduced by as much as $20 \% .{ }^{22}{ }^{23}$ It is unclear whether reduction in VGRF is due to the constant feedback (instruction effects) or actual neuromuscular adaptations. From an

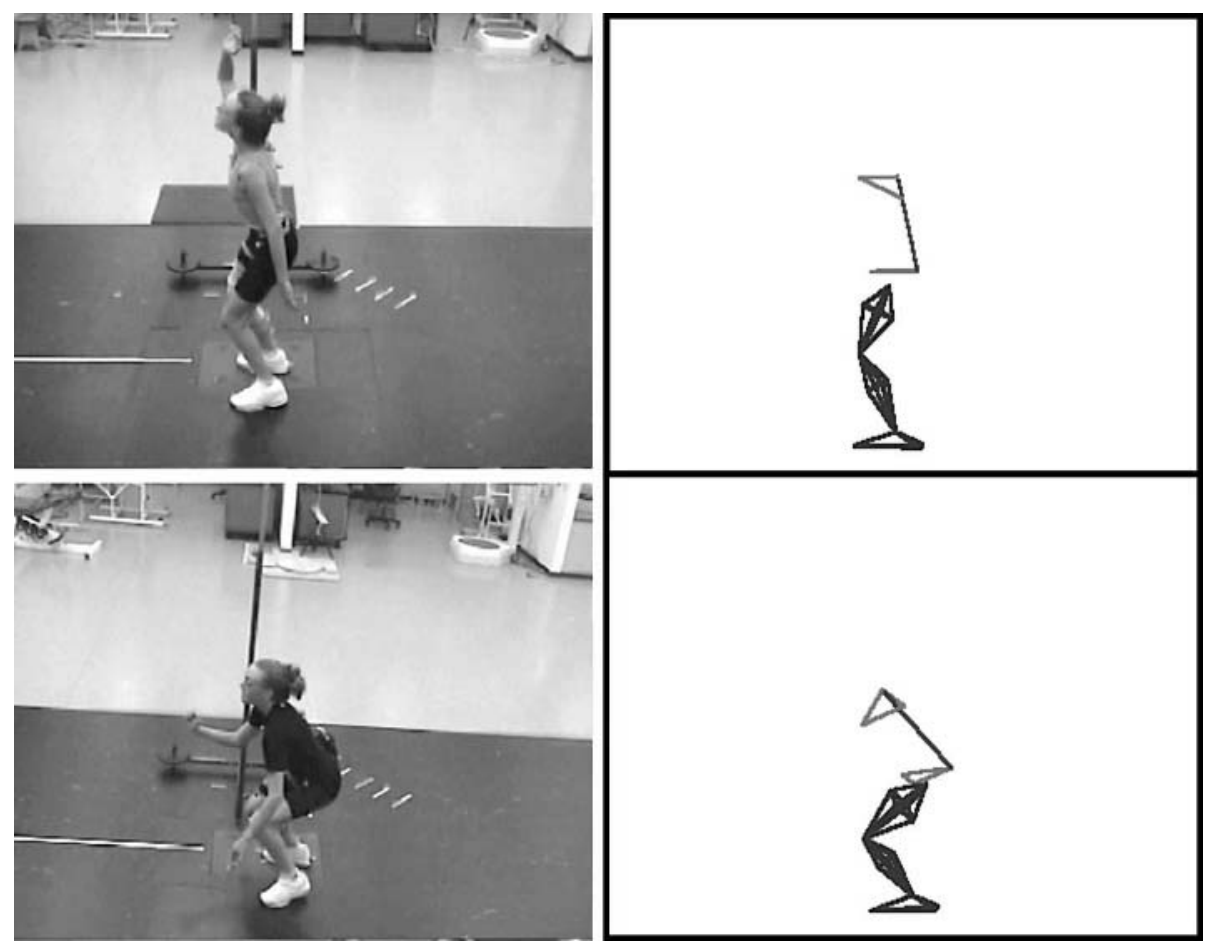

Figure 3 Peak knee flexion during jump-landing (pre-training $v$ post-training). (Photographs reproduced with permission.) 
Table 6 Integrated EMG data

\begin{tabular}{llll}
\hline EMG variables & & $\begin{array}{l}\text { Pretest } \\
\text { (\%MVIC*s) }\end{array}$ & $\begin{array}{l}\text { Post-test } \\
\text { (\%MVIC*s) }\end{array}$ \\
\hline Vastus lateralis & Plyometric & $0.014 \pm 0.008$ & $0.014 \pm 0.007$ \\
preactivity & Basic & $0.019 \pm 0.013$ & $0.022 \pm 0.013$ \\
Vastus lateralis & Plyometric & $0.064 \pm 0.02$ & $0.069 \pm 0.027$ \\
reactivity & Basic & $0.069 \pm 0.026$ & $0.087 \pm 0.039$ \\
Vastus medialis & Plyometric & $0.016 \pm 0.012$ & $0.021 \pm 0.022$ \\
preactivity & Basic & $0.027 \pm 0.015$ & $0.025 \pm 0.014$ \\
Vastus medialis & Plyometric & $0.088 \pm 0.055$ & $0.105 \pm 0.043$ \\
reactivity & Basic & $0.13 \pm 0.024$ & $0.133 \pm 0.072$ \\
Lateral hamstring & Plyometric & $0.016 \pm 0.018$ & $0.014 \pm 0.01$ \\
preactivity & Basic & $0.017 \pm 0.013$ & $0.019 \pm 0.018$ \\
Lateral hamstring & Plyometric & $0.035 \pm 0.037$ & $0.042 \pm 0.071$ \\
reactivity & Basic & $0.025 \pm 0.013$ & $0.065 \pm 0.114$ \\
Medial hamstring & Plyometric & $0.014 \pm 0.009$ & $0.018 \pm 0.014$ \\
preactivity & Basic & $0.011 \pm 0.007$ & $0.016 \pm 0.012$ \\
Medial hamstring & Plyometric & $0.026 \pm 0.018$ & $0.027 \pm 0.021$ \\
reactivity & Basic & $0.014 \pm 0.006$ & $0.033 \pm 0.042$ \\
Gluteus medius & Plyometric & $0.019 \pm 0.014$ & $0.04 \pm 0.033$ \\
preactivity* & Basic & $0.024 \pm 0.013$ & $0.037 \pm 0.028$ \\
Gluteus medius & Plyometric & $0.038 \pm 0.024$ & $0.099 \pm 0.11$ \\
reactivity* & Basic & $0.052 \pm 0.03$ & $0.154 \pm 0.16$ \\
\hline
\end{tabular}

*Significant main effect pretest-posttest differences at $p<0.05$.

injury prevention standpoint, it is important to minimise vGRF during landing, but stiffer landing and shorter foot contact time are necessary for better athletic performance in stretch-shortening cyclic movements such as running, bounding, and repeated jumping. ${ }^{24}$ Future studies will be needed to address the relationship and roles of vGRF in injury prevention and athletic performance.

Hip flexion at initial contact and peak knee and hip flexion were increased in both groups, supporting our hypotheses. Increased hip flexion, peak knee flexion, and time to peak knee flexion during the jump-landing task enable the body to more effectively absorb joint forces while promoting the mechanical advantage of the soft tissue structures to provide joint stability. ${ }^{25}$ The degree of knee flexion during landing activities has been reported to influence the body's ability to attenuate joint forces. ${ }^{26}$ Additionally, increased knee flexion and hip flexion during landing tensions the hamstring muscles to provide a posterior force upon the knee to protect the ACL. ${ }^{28}$ This contention is further supported by the increased peak hip and knee flexion moment during the landing.

Improvements in integrated and time to peak EMG activity of the gluteus medius prior to the initial contact with the ground indicated that subjects may position the thigh prior to ground contact in anticipation of the impact forces at landing that would cause hip adduction and knee valgus. ${ }^{29}{ }^{30}$ The gluteus medius may enhance knee stability by limiting hip adduction and knee valgus during the landing portion of a jumping task. Although we did not find significant changes in hip adductor strength, the current finding was similar to that of a previous study, ${ }^{15}$ in which the authors reported earlier onset of both hip abductor and adductor EMG after 6 weeks of plyometric training. The strategy and importance of thigh and hip musculature control has been demonstrated in other studies. ${ }^{31}{ }^{32}$ Despite the lack of significant findings in kinematics and kinetics in hip and knee abduction/adduction positions and moments, subjects might have maintained hip control by increasing the gluteus medius integrated EMG and timing to minimise joint displacement in the frontal and transverse planes and to optimise the primary rotators (flexor/extensor) in the sagittal plane to absorb and utilise the forces and energy effectively.

Recent evidence suggests that the medial and lateral hamstrings are selectively activated to control internal and external rotations of the tibia, and EMG activity of lateral hamstrings during the pre-landing phase of cutting manoeuvres may be a critical factor for preventing such rotation. $^{33}$ In the current study, a significant group interaction was observed for medial hamstring reactivity time. The plyometric group had less time to the peak reactivity EMG in the medial hamstrings after foot contact. As subjects learned to jump and land during the plyometric exercises, they might have also learned to activate less medial hamstrings to maximise the effect of lateral hamstrings in order to stabilise the knee against internal/external rotational torque. The current study did not find significant differences in the lateral hamstring EMG time or integrated EMG (iEMG); however, there was a trend that the onset of the peak preactivity EMG of the lateral hamstring was $43 \%$ earlier only for the plyometric group, and the iEMG increased $27-46 \%$ in both groups. Viitasalo et al ${ }^{35}$ compared elite jumpers and controls as regards jumping mechanics and EMG, and reported much greater activation of the lateral hamstring during the pre-landing phase. This EMG strategy on the lateral hamstring is also apparent for ACL deficient "copers" who can participate in sports without any problems or instability. ${ }^{36}{ }^{37}$ This may be one advantage of including some type of plyometric and jumping exercises in the program to optimise the activation of the lateral hamstring prior to foot contact. Recent computer injury simulation studies $^{38} 39$ reported that secondary rotations (valgus/varus and internal/external rotations of the tibia) are responsible for most non-contact ACL injuries. The role of secondary rotations and muscular contributions to such rotations should be investigated in the future.

The current study has several limitations. First, no "true" control group was assessed, and the non-participating subjects may have achieved similar neuromuscular adaptations despite their non-participating group status. Second, the current exercise programs were home based, and although exercise performance was regularly monitored, true compliance was unknown. Third, the 4 week volume of agility and plyometric training for the plyometric program may not have had sufficient time to induce an additional neuromuscular and biomechanical benefit.

\section{CONCLUSION}

The results of this study suggest that the neuromuscular characteristics of the lower extremity in female athletes can

\section{What is already known on this subject}

Numerous injury prevention programs have been developed and have successfully reduced the number of knee ligament injuries. However, few have investigated the neuromuscular and biomechanical changes following these training programs. It is also largely unknown what type of program is better for improving the landing mechanics of female athletes.

\section{What this study adds}

The results of this study suggest that the neuromuscular characteristics of the lower extremity in female athletes can be improved with a basic exercise program alone, potentially reducing at risk injury positions during a drop-landing. Additionally, a plyometric program may further be utilised to improve muscular activation patterns. 
be improved with a basic exercise program alone, potentially reducing at risk injury positions during a drop-landing. This result favourably supports the study by Lehnhard et al ${ }^{13}$ who reported a reduction in injury rate after a strength training program alone. Additionally, a plyometric program may further be utilised to improve muscular activation patterns. Future research should examine the long term effects of basic and plyometric or a combined program with an increased stimulus to promote dynamic knee stability. Only prospective studies involving a large number of participants will determine the true effects of plyometric and basic programs on ACL injuries in female athletes.

\section{Authors' affiliations}

S M Lephart, J P Abt, C M Ferris, T C Sell, T Nagai, J B Myers, J J Irrgang, Neuromuscular Research Laboratory, University of Pittsburgh, Pittsburgh, PA, USA

We would like to thank the Jewish Healthcare Foundation for their generous support of this project

Competing interests: none declared

The photographs in this article are reproduced with the permission of the subjects

\section{APPENDIX A}

Table Al Phase I exercises: both groups (weeks 1-4)

\begin{tabular}{cl}
\hline Flexibility, 3 repetitions (30 s) & Resistance, 20 repetitions \\
Quadriceps & Lateral step down \\
Hamstrings & Calf raises \\
Hip flexors & Theraband, leg curls \\
Tensor fascia latae & Theraband, leg extensions \\
Hip adductors & Theraband, squats \\
Calf & Abdominal curl ups \\
Balance, 3 repetitions (15 s) & Side bridging, bent knees \\
Single leg balance & Forward/lateral lunges \\
Single leg balance, flexed knee & Single leg hip hike \\
Single leg balance perturbations & Standing hip rotations \\
\hline
\end{tabular}

Table All Phase II exercises: plyometric group (weeks 58)

\begin{tabular}{ll}
\hline Flexibility, 3 repetitions (30 s) & $\begin{array}{c}\text { Resistance, } 30 \text { repetitions } \\
\text { Quadriceps }\end{array}$ \\
Single leg squat \\
Hamstrings & Calf raises, single leg \\
Hip flexors & Theraband, leg curls \\
Tensor fascia latae & Theraband, leg extensions \\
Hip adductors & Theraband, squats \\
Calf & Abdominal curl ups \\
Plyometrics, 10 repetitions & Side bridging, straight knees \\
Single/double leg forward hops & Forward/lateral/diagonal lunges \\
Single/double leg broad jump & Single leg hip hike \\
Single/double leg jump from & Forward lean hip rotations \\
box & Agility, 5 repetitions \\
Double leg backward hops & Shuttle runs \\
Double leg lateral hops & $45^{\circ}$ cuts: side/cross; $90^{\circ}$ cuts: side \\
Double leg squat thrusts & Butt kicks \\
Double leg jump-lunge-jump & Forward/backward cut and spin \\
Double leg jump from box & High knees \\
Scissors jumps & Side sliding \\
Triple hops & Cariocas \\
Balance, 3 repetitions (10 s) & \\
Single leg balance & \\
Single leg balance, flexed knee & \\
Single leg balance perturbations & \\
\hline
\end{tabular}

Table All Phase II exercises: basic group (weeks 5-8)

\begin{tabular}{ll}
\hline Flexibility, 3 repetitions (30 s) & Resistance, 30 repetitions \\
Quadriceps & Single leg squat \\
Hamstrings & Calf raises, single leg \\
Hip flexors & Theraband, leg curls \\
Tensor fascia latae & Theraband, leg extensions \\
Hip adductors & Theraband, leg squats \\
Calf & Abdominal curl ups \\
Balance, 3 repetitions (10 s) & Side bridging, straight knees \\
Single leg balance & Forward/lateral/diagonal lunges \\
Single leg balance, flexed knee & Single leg hip hike \\
Single leg balance perturbations & Forward lean hip rotations \\
\hline
\end{tabular}

\section{REFERENCES}

1 Arendt E, Agel J, Dick R. Anterior cruciate ligament injury patterns among collegiate men and women. J Athl Train 1999;34:86-92.

2 Powell JW, Barber-Foss KD. Sex-related injury patterns among selected high school sports. Am J Sports Med 2000;28:385-91.

3 Lephart SM, Ferris CM, Riemann BL, et al. Gender differences in strength and lower extremity kinematics during landing. Clin Orthop 2002;401:162-9.

4 McLean SG, Lipfert SW, van den Bogert AJ. Effect of gender and defensive opponent on the biomechanics of sidestep cutting. Med Sci Sports Exerc 2004;36:1008-16

5 Decker MJ, Torry MR, Wyland DJ, et al. Gender differences in lower extremity kinematics, kinetics and energy absorption during landing. Clin Biomech (Bristol, Avon) 2003;18:662-9.

6 Pincivero DM, Gandaio CM, Ito Y. Gender-specific knee extensor torque, flexor torque, and muscle fatigue responses during maximal effort contractions. Eur J Appl Physiol 2003;89:134-41.

7 Rozzi SL, Lephart SM, Gear WS, et al. Knee joint laxity and neuromuscular characteristics of male and female soccer and basketball players. Am J Sports Med 1999;27:312-19.

8 Hewett TE, Lindenfeld TN, Riccobene JV, et al. The effect of neuromuscular training on the incidence of knee injury in female athletes. A prospective study. Am J Sports Med 1999;27:699-706.

9 Myklebust G, Engebretsen L, Braekken IH, et al. Prevention of anterior cruciate ligament injuries in female team handball players: a prospective intervention study over three seasons. Clin J Sport Med 2003;13:71-8.

10 Heidt RS Jr, Sweeterman LM, Carlonas RL, et al. Avoidance of soccer injuries with preseason conditioning. Am J Sports Med 2000;28:659-62.

11 Caraffa A, Cerulli G, Projetti M, et al. Prevention of anterior cruciate ligament injuries in soccer. A prospective controlled study of proprioceptive training Knee Surg Sports Traumatol Arthrosc 1996;4:19-21.

12 Wedderkopp N, Kaltoft M, Holm R, et al. Comparison of two intervention programmes in young female players in European handball - with and without ankle disc. Scand J Med Sci Sports 2003;13:371-5.

13 Lehnhard RA, Lehnhard HR, Young R, et al. Monitoring injuries on a college soccer team: the effect of strength training. J Strength Cond Res $1996: 10: 115-9$.

14 Hewett TE, Stroupe AL, Nance TA, et al. Plyometric training in female athletes. Decreased impact forces and increased hamstring torques. Am J Sports Med 1996;24:765-73.

15 Chimera NJ, Swanik KA, Swanik CB, et al. Effects of plyometric training on muscle-activation strategies and performance in female athletes. J Athl Train 2004;39:24-31.

16 Woitys EM, Huston $\amalg$, Taylor PD, et al. Neuromuscular adaptations in isokinetic, isotonic, and agility training programs. Am J Sports Med 1996;24:187-92.

17 Vaughan CL, Davis BL, O'Connor JC. Dynamics of human gait. Cape Town: Kiboho, 1991.

18 Yu B, Gabriel D, Noble L. Estimate of optimum cutoff frequency for a low-pass digital filter. J Appl Biomech 1999;15:318-29.

19 Kadaba MP, Ramakrishnan HK, Wootten ME, et al. Repeatability of kinematic, kinetic, and electromyographic data in normal adult gait. J Orthop Res 1989;7:849-60.

20 Huston L, Wojtys EM. Neuromuscular performance characteristics in elite female athletes. Am J Sports Med 1996;24:427-36.

21 Irmischer BS, Harris C, Pfeiffer RP, et al. Effects of a knee ligament injury prevention exercise program on impact forces in women. J Strength Cond Res 2004;18:703-7.

22 Onate JA, Guskiewicz KM, Sullivan RJ. Augmented feedback reduces jump landing forces. J Orthop Sports Phys Ther 2001;31:511-7.

23 Prapavessis $\mathrm{H}, \mathrm{McNair}$ PJ. Effects of instruction in jumping technique and experience jumping on ground reaction forces. J Orthop Sports Phys Ther 1999;29:352-6.

24 Horita T, Komi PV, Nicol C, et al. Interaction between pre-landing activities and stiffness regulation of the knee joint musculoskeletal system in the drop jump: implications to performance. Eur J Appl Physiol 2002;88:76-84.

25 Devita P, Skelly WA. Effect of landing stiffness on joint kinetics and energetics in the lower extremity. Med Sci Sports Exerc 1992;24:108-15.

$26 \mathrm{McNitt-Gray} \mathrm{JL}$. Kinetics of the lower extremities during drop landings from three heights. J Biomech 1993;26:1037-46. 
27 Renstrom P, Arms SW, Stanwyck TS, et al. Strain within the anterior cruciate ligament during hamstring and quadriceps activity. Am J Sports Med 1986;14:83-7.

28 Hirokawa S, Solomonow M, Luo Z, et al. Muscular co-contraction and control of knee stability. J Electromyogr Kinesiol 1991;1:199-208.

29 Zeller BL, McCrory JL, Kibler WB, et al. Differences in kinematics and electromyographic activity between men and women during the single-legged squat. Am J Sports Med 2003;31:449-56.

30 Ferber $\mathbf{R}$, Davis IM, Williams DS 3rd. ender differences in lower extremity mechanics during running. Clin Biomech (Bristol, Avon) 2003;18:350-7.

31 Lloyd DG, Buchanan TS. Strategies of muscular support of varus and valgus isometric loads at the human knee. J Biomech 2001;34:1257-67.

32 Zhang LQ, Wang G. Dynamic and static control of the human knee joint in abduction-adduction. J Biomech 2001;34:1107-15.

33 Besier TF, Lloyd DG, Ackland TR. Muscle activation strategies at the knee during running and cutting maneuvers. Med Sci Sports Exerc 2003;35:119-27.
34 Ciccotti MG, Kerlan RK, Perry J, et al. An electromyographic analysis of the knee during functional activities. I. The normal profile. Am J Sports Med 1994;22:645-50.

35 Viitasalo JT, Salo A, Lahtinen J. Neuromuscular functioning of athletes and non-athletes in the drop jump. Eur J Appl Physiol Occup Physiol 1998;78:432-40.

36 Alkjaer T, Simonsen EB, Jorgensen $U$, et al. Evaluation of the walking pattern in two types of patients with anterior cruciate ligament deficiency: copers and non-copers. Eur J Appl Physiol 2003;89:301-8.

37 Rudolph KS, Axe MJ, Buchanan TS, et al. Dynamic stability in the anterior cruciate ligament deficient knee. Knee Surg Sports Traumatol Arthrosc $2001 ; 9: 62-71$

38 McLean SG, Huang X, Su A, et al. Sagittal plane biomechanics cannot injure the $\mathrm{ACL}$ during sidestep cutting. Clin Biomech (Bristol, Avon) 2004; 19:828-38.

39 Pflum MA, Shelburne KB, Torry MR, et al. Model prediction of anterior cruciate ligament force during drop-landings. Med Sci Sports Exerc 2004;36:1949-58.

\section{bmjupdates+}

bmjupdates+ is a unique and free alerting service, designed to keep you up to date with the medical literature that is truly important to your practice.

bmjupdates+ will alert you to important new research and will provide you with the best new evidence concerning important advances in health care, tailored to your medical interests and time demands.

Where does the information come from?

bmjupdates+ applies an expert critical appraisal filter to over 100 top medical journals A panel of over 2000 physicians find the few 'must read' studies for each area of clinical interest

Sign up to receive your tailored email alerts, searching access and more...

www.bmjupdates.com 